\title{
Agency, Values, and Well-Being: A Human Development Model
}

\author{
Christian Welzel $\cdot$ Ronald Inglehart
}

Accepted: 10 November 2009/Published online: 18 February 2010

(C) The Author(s) 2010. This article is published with open access at Springerlink.com

\begin{abstract}
This paper argues that feelings of agency are linked to human well-being through a sequence of adaptive mechanisms that promote human development, once existential conditions become permissive. In the first part, we elaborate on the evolutionary logic of this model and outline why an evolutionary perspective is helpful to understand changes in values that give feelings of agency greater weight in shaping human well-being. In the second part, we test the key links in this model with data from the World Values Surveys using ecological regressions and multi-level models, covering some 80 societies worldwide. Empirically, we demonstrate evidence for the following sequence: (1) in response to widening opportunities of life, people place stronger emphasis on emancipative values, (2) in response to a stronger emphasis on emancipative values, feelings of agency gain greater weight in shaping people's life satisfaction, (3) in response to a greater impact of agency feelings on life satisfaction, the level of life satisfaction itself rises. Further analyses show that this model is culturally universal because taking into account the strength of a society's western tradition does not render insignificant these adaptive linkages. Precisely because of its universality, this is indeed a 'human' development model in a most general sense.
\end{abstract}

Keywords Agency feelings · Cultural evolution · Emancipative values · Human development · Knowledge economies · Life satisfaction · Well-being

\section{Introduction}

This paper claims that people can and do change their strategies to maximize happiness and that changes in value priorities are an inherent part of this process. Furthermore, we

C. Welzel $(\bowtie)$

School of Humanities and Social Sciences, Jacobs University Bremen gGmbH,

Campus Ring 1, Research IV, Room 62 a/b, 28759 Bremen, Germany

e-mail: cwelzel@gmail.com

R. Inglehart

University of Michigan, Ann Arbor, MI, USA 
claim that in order to understand the logic of these changes, one has to start from an evolutionary model of social change (Nolan and Lenski 1999; Carneiro 2003; Boyd and Richardson 2005). An evolutionary model recognizes that people adapt their maximization strategies in response to the shifting needs and opportunities of life (Parsons 1964; Dunbar et al. 1999). When these needs and opportunities shift in the same way for many people, this nurtures similar adaptation strategies. Similar strategies accumulate to collective trends, which is social change. Social change of this accumulative type is evolutionary in the sense that it is self-driven: it needs no central coordinator with a master plan to merge the adaptations of many people into a collective trend when the 'invisible hand' of the adaptive logic does the job (Axelrod 1986; Coleman 1990).

Evolutionary dynamics always favor what is most adaptive under given circumstances (Durham 1991). Both human individuals and societies are adaptive when they command two types of capabilities: (a) the capability to meet the needs that have to be met in order to survive; and (b) the capability to take the opportunities that have to be taken in order to thrive. Among individuals as well as societies, the imperative of adaptability puts a premium on 'agency.' Greater agency involves higher adaptability because for individuals as well as societies, agency means the power to act purposely to their advantage (Bakan 1966; McAdams 1993; Guisinger and Blatt 1994). As Birch and Cobb (1981) outline in The Liberation of Life, one can see the evolutionary trend to increase agency both in the biological evolution of organisms and in the social evolution of civilization. Life evolved from lower to higher organized organisms and this was a move from low agency, as in microbes and insects, to high agency as in primates and above all humans, with the latter being more empowered to act purposely to their advantage than any other species on earth. Civilizations, too, evolved from technologically less to technologically more empowered societies, in a sequence from hunter-gatherer to agrarian to industrial to postindustrial societies, with the latter exerting the most power over their environments (Elias 2004 [1984]; Nolan and Lenski 1999).

In the evolution of life, agency became most advanced in human beings as the species with the highest intellectual power to act with purpose on this planet. As an evolutionary shaped capacity, agency is a particularly 'human' capacity. It is indeed a defining characteristic of our species (Maryanski and Turner 1992). 'Human' development is hence any development that promotes the most human trait—agency (Sen 1999). In the life course of individuals, human development is the maturation of a person's agentic traits. Applying the same logic to the trajectory of societies, all changes that bring a larger number of people in the situation to more fully realize their agentic traits, is to be characterized as 'human' development (Welzel et al. 2003).

As we will try to show, variation in life strategies within and between societies reflect evolutionary adaptations to changing living conditions in ways that favor agency and hence, human development. And as we will see, as an evolutionary shaped trait, agency is anchored in the human motivational system in that greater feelings of agency yield higher life satisfaction. The rootedness of agency in the human motivational system is, as we claim, the key driver of human development. Yet, the way in which agency is rooted in the human motivational system also explains why human development does often not proceed. The key reason lies in the fact that the weight with which feelings of agency impact on human life satisfaction varies with the character of life. When life is a constant threat to suffer, people place less emphasis on agency; only when life becomes an opportunity to thrive, do people begin to value agency very highly. From a different conceptual angle and with different methodology, the findings of Delhey (2010) on "postmaterialist happiness" point to the same conclusion as ours. 
The article is composed as follows. In the first part, we argue why an evolutionary perspective is helpful to understand social change. Specifically, this applies to changes in values that give feelings of agency greater weight in shaping human well-being. In the second part, we test the key links in this model with data from the World Values Surveys using ecological regressions and multi-level models, covering some 80 societies worldwide. Empirically, we demonstrate evidence for the following sequence: (1) in response to widening opportunities of life, people place stronger emphasis on emancipative values, (2) in response to a stronger emphasis on emancipative values, feelings of agency gain greater weight in shaping people's life satisfaction, (3) in response to a greater impact of agency feelings on life satisfaction, the level of life satisfaction itself rises. Further analyses show that this model is culturally universal because taking into account the strength of a society's western tradition does not render insignificant these adaptive linkages. Precisely because of its universality, this is indeed a 'human' development model in a most general sense.

\section{Theory}

Like everything that is part of life, human societies develop under the evolutionary imperative to adapt to the conditions of their environment. Otherwise they are not viable (Parsons 1964; Elias (2004 [1984]); Nolan and Lenski 1999; Diamond 2005; Barber 2008). Human societies operate under adaptive pressures as regards the patterns of (a) how they organize themselves and (b) how they orientate themselves (Dunbar et al. 1999). The first aspect relates to structural adaptability, the second to cultural adaptability. By means of historical experiments, some societies might have found patterns of organization and orientation that are better for a society to master given needs and opportunities, making these societies thriving. This creates social models that, once they are recognized as such, tend to diffuse among societies. At some point in history, each society makes distinct choices about which model to adopt. 'Evolutionary universals' (Parsons 1964) such as state bureaucracy, market capitalism, the welfare state and electoral democracy diffused in the past because the elites of societies recognized these as social models and deliberately chose to adopt them because of their utility (Modelski and Gardner 2002; Meyer et al. 1997). The Prussian Reforms of 1811-1813, the Meiji-Period in Japan and the numerous examples when countries change their political regime or economic order fall into this category.

Social evolution proceeds at different levels. One is the level of societies themselves. Here evolution proceeds through historical sequences of collective choices exacted by societal elites. This includes choices about wars, international alliances, political regimes, economic orders, and policy programs. But the imperatives of adaptation operate also on the micro level of individual human beings. Their capacities to exert agency enable them to make choices about what to maximize in their lives. Because these choices are not fully predetermined, they differ. Differences manifest variation in human maximization strategies. Variation in a pool of strategies establishes a field of experimentation that filters out what is more useful under what conditions. Among perceptive agents this makes learning possible, allowing individuals to chose the strategies they perceive as most useful. When many such micro-level choices are similar, they create a macro-level trend that changes entire societies (Boyd and Richardson 2005).

Quite logically, when maximization strategies change, the values that legitimize and inspire these strategies change with them. Value change can hence be described as an evolutionary process that follows Coleman's (1990) 'bath tub model': similar choices at 
the micro-level create a macro-level trend that changes society. Axelrod (1986), for instance, explains changes in societal norms using this adaptive evolutionary logic. And Elias (2004 [1984]) holds that when processes are clearly directed, even though they are neither centrally planned nor coordinated, employing evolutionary logic is the only way to understand such processes.

As an evolutionary process, value change involves humans as agents who make distinct strategy choices. Agency, understood as the capacity to make purposeful choices, and the learning potential connected to agency, catapult the evolutionary pace of human societies on a new level, accelerating cultural evolution way beyond biological evolution (Elias (2004 [1984]); Durham 1991; Carneiro 2003).

Most theories of value change, including Inglehart's (1977, 1990) generational replacement thesis, follow an evolutionary logic, even if they are not explicit about this. This is true for three reasons. First, values are assumed to change in adaptation to changing living conditions. In Inglehart's thinking these are generational adaptations to changing living conditions in people's formative years. Second, the adaptation happens at the microlevel and when many micro-level adaptations move in the same direction, they accumulate to a macro-level trend. Third, these adaptations are not centrally planned or 'socially constructed': no central actor controls them. It is the invisible-hand like logic of adaptation that leads agents who are capable of choice to adopt similar strategies.

The function of values is to inspire maximization strategies that help agents to master two things with which any environment confronts them: needs and opportunities. Meeting needs is necessary to survive. Taking opportunities is helpful to thrive. Like anything that is a property of living beings, values operate under the imperative to respond to the needs and opportunities of their environment. Values inspire maximization strategies and different maximization strategies are differently useful in meeting needs and taking opportunities. Strategies that are not useful in meeting given needs are not viable. They are deselected by the failure of the agents who apply them. With the non-viable strategies, the values that inspire them are deselected too. Such negative selection does not require any attempt at learning among the involved agents. It always works: anything that is not reality-fit is deselected by reality.

'Negative' selection always reduces the pool of existing life models to what is viable. But even though all existing models in a given pool are viable by definition, some might be more useful than others for thriving. Agents whose values inspire strategies that are more useful in taking advantage from given opportunities will thrive more. They will be better off, which will become manifest in recognizable signs of success. This sets the stage for 'positive' selection. Positive selection goes beyond deselecting the unviable but it only works in a population of agents whose intellectual capacities empower them to learn from observation and change their actions and strategies at own will. In a social setting, positive selection operates via the markers of success that flag out the thriving agents as role models for others to emulate. Human societies are unique in their potential for positive selection because they consist of agents who are particularly perceptive of social markers and who have a unique ability to adopt at will what they see as a useful model (Boyd and Richardson 2005).

Still, people's capacity of agency does by no means fully and freely unfold. Instead, people's agency is socially constrained in manifold ways. Humans grow up and live in stratified societies. Stratification is connected to the vested interests of the powerful. These interests are never openly propagated but instead are wrapped into legitimizing ideologies whose purpose is to make stratification accepted, especially among those who are at the 
lower end. These legitimizing ideologies are made credible and reproduced by another powerful tool that delimits human agency: socialization.

Socialization denotes the processes through which humans are familiarized with what is socially accepted in their society. Refusing to internalize these 'lessons' is socially sanctioned in manifold ways. These sanctions are successful because humans have evolved as social beings who are highly susceptible to group pressures (Tooby and Cosmides 2005). ${ }^{1}$ Accordingly, humans internalize most of their values fully unconsciously in an unquestioned process of socialization. ${ }^{2}$ Values are powerful regulators of human behavior because they are part of people's self-construal and identity. The personality aspect of values further limits humans' capacity to freely change and adjust their values (Kluckhohn 1951; Rokeach 1968; Schwartz 2007).

Not enough with that, stratification limits the horizon within which human agents look for useful role models. A peasant in a feudal society simply does not consider a knight as her/his role model because what the knight can achieve is beyond the peasant's perceived reach. More generally, stratification locks humans into separated reference groups. The more rigid stratification is, the more is social learning, role model diffusion, and positive selection bound within narrow reference groups.

All this means that value change is not coming about easily. Humans do not unnecessarily experiment with their values because experimentation is costly. It means breaking with given conventions and this involves social sanctions. And yet, humans are not deterministically programmed computers. Stratification, socialization, and the encoding of norms all work to reproduce a society's evolved configuration from one generation to the next. And for that to be possible, the individual human agents' capacities to change their values at own will has to be caged (Elias 2004 [1984]; Maryanski and Turner 1992). Still, as much as socialization 'cages' humans' agentic capacities, it does not set them off. In fact, when the environment changes so drastically that it poses new challenges or offers new opportunities, and when the challenges question the viability of old strategies, or when the old strategies are no longer useful to take advantage of the new opportunities, people's readiness to try out new strategies increases considerably. Experimentation will climb to new levels. This is to happen most frequently among younger people because for them experimentation is less costly (Flanagan 1987; Inglehart 1997). Having less of a lifetime invested into old values and role models, they can more easily detach their identity from traditional patterns. New lifestyles seek to create their own environment in which to thrive and this creates new social milieus. If a variety of such milieus emerges, other people are confronted with a greater variety of life models to choose from Flanagan and Lee (2001). Since humans are perceptive agents and because there are recognizable social markers of success, people will figure out which models are most useful in taking advantage of new opportunities. Many people will then adopt the values inspiring these models, resulting in a social diffusion of new values. If this happens, we observe an evolutionary change of norms, as described by Axelrod (1986).

\footnotetext{
1 Responsiveness to conformity pressures can lead to the adoption of behavior that is socially adaptive because it avoids sanctions but which is harmful for the well-being of the individual and even an entire society. Societies whose conformity pressures cause harmful behavior are themselves maladaptive, which in the extreme case can lead to their "Collapse" (Diamond 2005).

${ }^{2}$ Often, people develop rational arguments to legitimize their values. But the values have not been chosen on the basis of logical reasoning. Rather, rationality is constructed to justify a priori internalized values.
} 


\subsection{An Evolutionary Model of Sequential Adaptive Mechanisms}

Elaborating on a sequence of adaptations entailed in the human development model of Welzel et al. (2003), Fig. 1 shows an evolutionary sequence of cultural change, involving four adaptive links. These links are in a sequential order of ontological priority. First, there is an environment-utility link through which given existential conditions define the availability of opportunities to thrive. Existential conditions are all types of environmental conditions, including not only natural conditions but also economic, social, and cultural conditions. Consider for instance an economic condition: a society subsists as an agrarian economy in which a large majority of the population is occupied in food production. Under this condition, obtaining university-level education is not an easily available opportunity for most people because agrarian societies do not provide extensive education. Even if an individual manages to attain a university degree, this is not a very useful opportunity to thrive in agrarian societies because there are few occupations for academically trained people in these types of societies. Education is of limited utility under these circumstances. Or consider a cultural condition: the norms of a society favor the male breadwinner model. Obtaining professional training is of limited utility especially for women under this condition. Even if they manage to receive professional training, lack of social acceptance of a female breadwinner would severely limit what women could do with training. Finally, consider a political condition: the denial of democratic freedoms, such as the right to vote government out of office. This restriction limits the utility of political information because, if one cannot use information to cast a vote that counts, getting information is pretty useless. There are many more examples of how economic, social, cultural and political conditions set limits to opportunities and their utility for people to thrive.

The environment-utility link is followed by a utility-value link: people prioritize the opportunities with the greatest utility in their society, so taking these opportunities becomes a widely supported value. In an agrarian society, for example, land property is valued. And when a society lacks an efficient pension system so that having many children provides an important opportunity to subsist in old age, fertility tends to be highly valued.

Next follows a value-strategy link: values inspire and legitimize certain maximization strategies. When, for instance, a woman values a life model that favors a double role as housewife and breadwinner, she is likely to adjust her maximization strategy accordingly. Instead of maximizing the time used for childcare, she will also invest time to obtain professional training.

Finally, there is a strategy-wellbeing link. Every strategy, if successfully realized, is a source of satisfaction. However, we claim that the type of strategy has different satisfying potential. Specifically, strategies that are targeted at unfolding agentic traits yield higher levels of satisfaction because they actualize an agentic being's inner traits. In a Maslowian logic (Maslow 1988 [1954]), agency provides the highest level of satisfaction because it meets the most uniquely human need, indeed the need of highest order in the evolution of life: self-actualization (Veenhoven 2000; Haller and Hadler 2004; Baumeister et al. 2009).

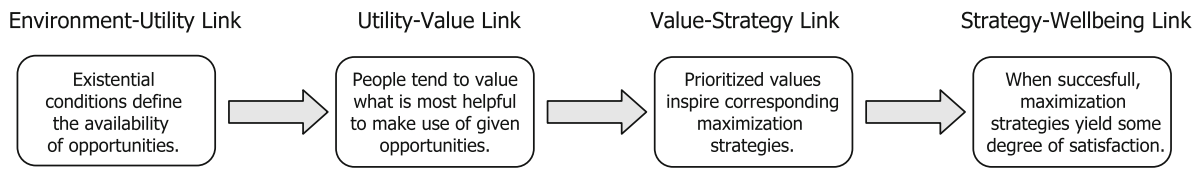

Fig. 1 An evolutionary sequence of adaptive links explaining social change 
The Human Stagnation Path

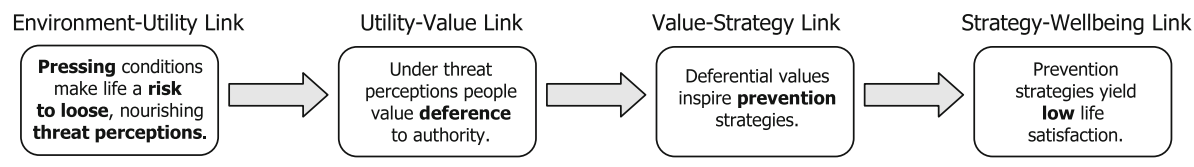

\section{The Human Development Path}

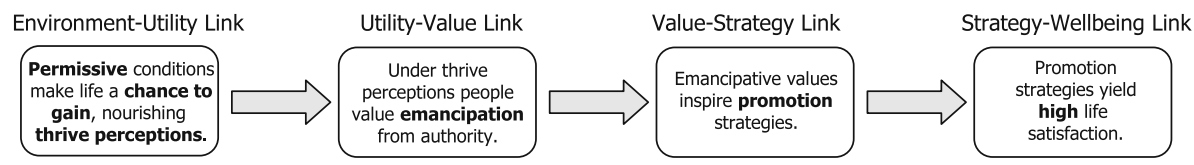

Fig. 2 Vicious and virtuous versions of the evolutionary model of social change

As outlined in the Liberation of Life by Birch and Cobb (1981), evolution generally pays a premium on agency because for an individual with greater agency more things become a useful opportunity. Self-actualization is the most agentic end among all and one of the 'tricks' of evolution to favor agency is to attach the highest satisfaction yield to selfactualization. Experimental evidence that self-actualization has indeed a high satisfaction payoff is provided in the framework of self-determination theory by Deci and Ryan (2000).

Figure 2 specifies a vicious and a virtuous pathway of this general sequence of adaptive links, distinguishing them by how inhibitive or favorable they are to human growth, unfolding, and development. Accordingly, the vicious pathway is labeled "human stagnation path" and the virtuous one is labeled "human development path." They are mirror images of each other.

Pressing existential conditions are found in societies on low levels of economic development. Life in these societies is shorter and harder and offers people less opportunities to thrive. Indeed, under pressing conditions life is a constant risk to loose, which makes life a constant source of threat perceptions. Threat perceptions lead people to search for shelter under the shielding roof of authoritatively ordered group life. In this mode, people value deference to group authority. Deferential values in turn inspire and legitimize prevention strategies. This makes prevention of failure people's chronic 'regulatory focus' in society. ${ }^{3}$ If successfully realized, prevention strategies provide relaxation from existential pressures. This is a source of satisfaction but not a very powerful one, for relaxation from pressure leaves the agentic need of actualizing oneself unsatisfied.

Economically advanced societies differ from economically less developed ones in practically all aspects of life. Economically advanced societies are characterized by permissive existential conditions that offer the average person a longer and more exciting life and manifold opportunities to thrive. To take advantage from these opportunities it is helpful when people adopt agentic orientations and emancipate themselves from group authority. Emancipative values in turn inspire and legitimize promotion strategies. If successfully realized, promotion strategies provide feelings of fulfillment- the most powerful source of satisfaction.

The key to make the lives of entire populations healthier, longer, richer and more meaningful is economic development (Reinert 2007). The source of economic

\footnotetext{
3 The distinction between a prevention and a promotion focus in regulatory focus theory is usually applied to variation in conditions between different short-term situations (Foerster et al. 1998). But the same logic can be applied to variation in conditions between different long-term conditions.
} 
development is knowledge, the basis of all agency (Warsh 2006). In order to thrive, societies have to generate and deploy knowledge and this requires the mobilization of the cognitive potential of the population on as broad a front as possible (Toffler 1990; Drucker 1993; Florida 2002). ${ }^{4}$ The need to mobilize cognitive potentials broadly makes discriminatory group boundaries that bloc certain social groups from opportunities dysfunctional. To get cognitive mobilization started, to keep it going, and to accelerate it, intellectual freedom and equality of opportunities become prime requirements. Thus, cognitive mobilization favors a type of orientation that emphasizes personal autonomy, equality of opportunities, tolerance, and democratic participation. Hence, cognitive mobilization should give rise to emancipative values that emphasize freedom of expression and equality of opportunities. Inglehart and Welzel (2005) and Welzel (2006, 2007) introduced scales of emancipative values that became known under the label 'self-expression values' because freedom of expression is one of the core components of these values.

Because self-expression values emphasize personal autonomy, people who adopt these values should find the feeling of being agents in shaping their lives more important. And when feelings of agency become more important in people's life, these feelings should obtain greater weight in shaping people's life satisfaction. Finally, realizing one's agency potential brings more satisfaction than other satisfying strategies because actualized agency leads to fulfillment - the most highly rewarded type of satisfaction among selfaware, agentic beings.

\section{Operationalization}

\subsection{Hypotheses}

Based on these reflections, three hypotheses can be formulated, each one covers one of the above described adaptive links:

1. There is a utility-values link that ties self-expression values to cognitive mobilization.

2. There is values-strategy link that ties agentic life strategies to self-expression values.

3. There is a strategy-wellbeing link that ties high levels of life satisfaction to agentic life strategies.

\subsection{Data and Measurements}

Our hypotheses propose some rather universal claims that are supposed to operate independent of the type of society under consideration. The very universality of these

\footnotetext{
${ }^{4}$ There is no ultimately accepted definition of 'cognitive mobilization' but the most often used sources are Inglehart's Culture Shift (1990) and Dalton's Citizen Politics (2006), both of which emphasize informational resources and intellectual skills as the two components of cognitive mobilization. For example, Dalton (2006:19) defines cognitive mobilization as a process through which more people acquire "the political resources and skills that prepare them to deal with the complexities of politics and reach their own decisions." Political resources and skills are understood here as informational resources and intellectual skills. The expansion of informational resources is related to the rise, spread, and reach of modern electronic mass media and information technology, while the increase and spread of intellectual skills is linked to rising levels of education and cognitive demands in modern occupations. The link to the core features of knowledge societies is thus obvious. Understanding the complexities of politics can certainly be extended to understanding the complexities of modern life in general and the term "reach their own decisions" makes the connection to agency obvious.
} 
propositions makes it necessary to test them on as broad a basis as possible. The widest array of societies that has ever been covered with questions on values, feelings of agency, and life satisfaction is provided by the European and World Values Surveys (henceforth: Values Surveys-VS). The VS have fielded a standardized questionnaire among nationally representative samples of residents (sampling between 1,000 and 3,000 respondents per country) in more than 90 societies on all inhabited continents, representing more than $90 \%$ of the world population. We use pooled VS data from rounds III (1995-1999), IV (20002001), and V (2005-2007), covering a roughly 10 year period from 1995 to 2005. Details on questionnaire wording, fieldwork organization and data access can be obtained at www.worldvaluessurvey.org.

One part of our analytical strategy is to examine how culturally specific or universal the linkages we propose are. From the viewpoint of cultural relativism, one might suspect that selfexpression values and feelings of agency are specifically western concepts that do not really apply to non-western cultures. If this were indeed true, the linkages we propose would not work once one takes into account the strength of a society's Western traditions. The question, however, is where the strength of a western cultural heritage becomes most manifest. Agreeing with Huntington (1996), we think that one of the most distinct societal products of the west is liberal democracy. The widely cited work of Acemoglu and Robinson (2006) supports this view. The concept of liberal democracy has been invented and further developed in the west and exists there for the longest time. This is especially for the Protestant West, which, according to Max Weber, represents the western liberal spirit most clearly. From the Protestant West, liberal democracy diffused into other regions in a sequence reflecting these regions' closeness to the west, moving to catholic countries and then to Far Eastern and African countries, being most delayed until today in the Middle East. These cultural differences are perfectly reflected in the length of time since a country has liberal democracy.

To measure the endurance of democracy, we use Gerring's 'democracy stock' indicator as of 1995 (Gerring et al. 2005). This variable adds up the democracy scores a society has accumulated over time on the Polity IV autocracy-democracy index (Marshall and Jaggers 2000) but depreciates scores from past years by $1 \%$ for each year they are preceding the reference year 1995. This index reflects a society's accumulated experience with liberal democracy with a premium on recent experience. ${ }^{5}$ For the reasons just outlined, we interpret the democracy stock variable as an indication of the strength of western traditions in a society and label it accordingly.

To measure how advanced cognitive mobilization is in a society we use the World Bank's "knowledge index" (KI) as of 1995, which indicates "a society's ability to generate, adopt and, diffuse knowledge. The KI is the simple average of the normalized scores of a society on the key variables in the three knowledge economy pillars: education, innovation, and ICT (World Bank 2008)." The knowledge index combines data on education (using indicators like the tertiary enrollment ratio), on innovation (using indicators like the number of patents per 10,000 inhabitants), and on information technology (using indicators like the number of internet hosts per 1,000 inhabitants). We rescaled the index into a range from 0 to 1.0 , with higher values indicating a more advanced knowledge economy. A description of index construction and data are available for download at: http://info.worldbank.org/etools/kam2/KAM_page5.asp. In the following analyses, we label this variable "cognitive mobilization."

Self-expression values comprise a conglomerate of egalitarian, liberal, autonomous and expressive orientations. These orientations cohere more as aggregate properties of

\footnotetext{
${ }^{5}$ We thank John Gerring for his generosity in sharing his data with us.
} 
populations than as personal attributes of individuals because there is more variance and covariance in these orientations between than within populations. Following Welzel (2007) we build a scale of self-expression values from VS data as shown in Table 1. The scale range is from 0 for someone holding the least expressive position in each of the four component orientations to 1.0 for someone holding the most expressive position in all of them.

Feelings of agency, often also called locus of control, are covered in the VS by question number V46, which asks: "Some people feel they have completely free choice and control over their lives, while other people feel that what they do has no real effect on what happens to them. Please use this scale where 1 means 'no choice at all' and 10 means 'a great deal of choice' to indicate how much freedom of choice and control you feel you have over the way your life turns out." We recoded responses into a normalized scale with a range from 0 for the least agentic position to 1.0 for the most agentic position.

Life satisfaction is addressed by VS question number V22, which asks: "All things considered, how satisfied are you with your life as a whole these days? Using this card on which 1 means you are 'completely dissatisfied' and 10 means you are 'completely satisfied' where would you put your satisfaction with your life as a whole?" We normalized life satisfaction into a scale range from 0 for the least satisfied position to 1.0 for the most satisfied one.

A huge and still growing literature on subjective wellbeing suggests that life satisfaction is influenced by many factors and agency is only one of them (for overviews see Veenhoven 2000; Lykken 2000; Diener et al. 2006). ${ }^{6}$ Material factors, such as someone's actual income, but even more so a person's subjective monetary saturation play also a role (Diener and Oishi 2000; Inglehart et al. 2008). To include monetary saturation in our consideration is theoretically intriguing because its materialist nature brings monetary saturation into a stark contrast to agency feelings as a more idealistic source of satisfaction. To measure subjective monetary saturation we use question number V68 of the VS, asking: "How satisfied are you with the financial situation of your household? Please use this card again to help with your answer." The show card depicts a 1-10 scale which we transformed into a normalized scale range from 0 for the least satisfied position to 1.0 for the most satisfied one.

Another satisfying factor that is often brought into contrast to agency is 'communion' (Bakan 1966; McAdams 1993; Guisinger and Blatt 1994). Thus, we test the possibility that agentic life strategies and communal life strategies are contradictory. To measure communion, we construct a composite index that combines people's emphasis on the family and friends as important life domains, using VS questions V4 and V5, in which people are asked to indicate the level of importance they ascribe to the family (V4) and friends (V5) on a four-point scale from "not at all important" to "very important." We average both importance levels into a scale from 0 for someone attributing no importance to both family and friends to 1.0 for someone attributing high importance to both. We interpret this scale as measuring people's communion emphasis. We will also use standard demographic controls to make sure that the effects of our potentially satisfying factors are not confounded by sex, age, income and education. ${ }^{7}$

\footnotetext{
${ }^{6}$ Further readings include Peterson et al. (2005), Hagerty and Veenhoven (2006).

7 Biological sex is measured in V235 of the VS by observation of the interviewer. We coded female sex as 1.0 and male sex as 0 . The age measure is taken from V237 of the VS and measures biological age in years. Household income is measured in V253 on a scale of 1 to 10 for national income brackets. We transformed this into a normalized scale with minimum 0 for the lowest and 1.0 for the highest income bracket. Level of education is measured in V238 on a 9-point scale from 1 for no education whatsoever to 9 for a university degree. We transformed this into a normalized scale with minimum 0 for the lowest level and 1.0 for the highest level of education.
} 


\begin{tabular}{|c|c|c|c|c|c|c|c|}
\hline 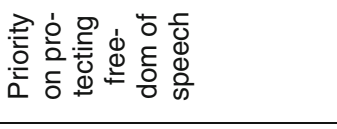 & $\bar{B}^{\circ} N$ & \multirow{3}{*}{ 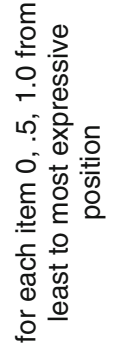 } & \multirow{3}{*}{$\underbrace{\overparen{8}}_{\substack{0 \\
0}}$} & \multirow{3}{*}{ 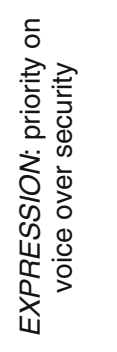 } & \multirow{3}{*}{ 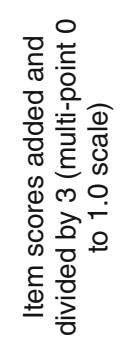 } & \multirow{14}{*}{ 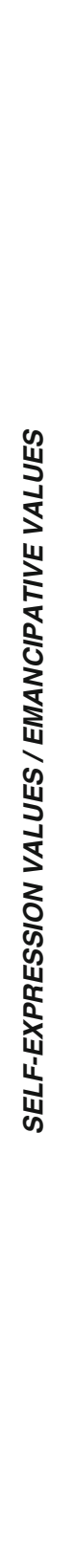 } & \multirow{14}{*}{ 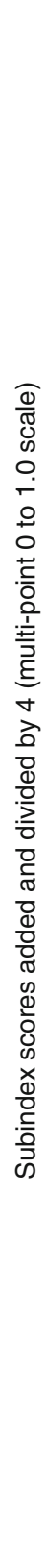 } \\
\hline 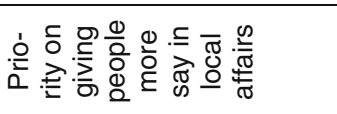 & gㅇ & & & & & & \\
\hline 은 은 & ${ }^{5} N$ & & & & & & \\
\hline 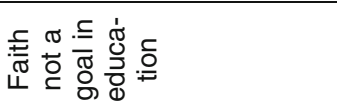 & $\bar{N}$ & \multirow{4}{*}{ 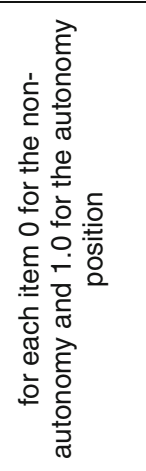 } & & \multirow{4}{*}{ 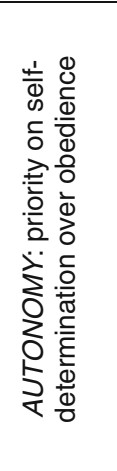 } & \multirow{4}{*}{ 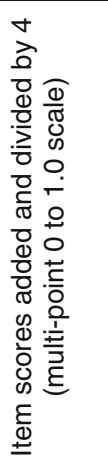 } & & \\
\hline 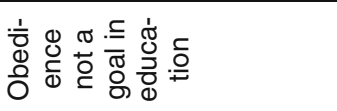 & $\stackrel{\infty}{>}$ & & & & & & \\
\hline 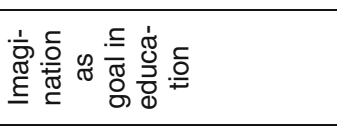 & $\stackrel{10}{>}$ & & & & & & \\
\hline 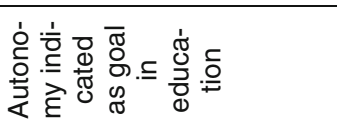 & $\stackrel{N}{\lessgtr}$ & & & & & & \\
\hline 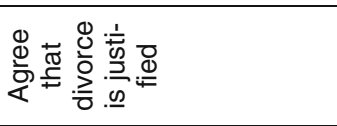 & 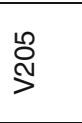 & \multirow{3}{*}{ 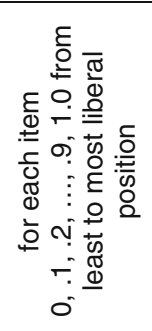 } & \multirow{3}{*}{ 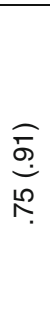 } & \multirow{3}{*}{ 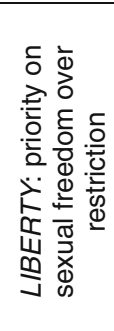 } & \multirow{3}{*}{ 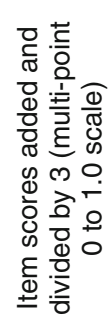 } & & \\
\hline 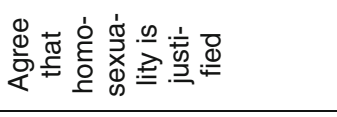 & ণิ & & & & & & \\
\hline 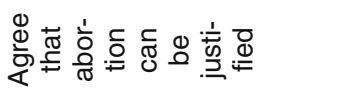 & $\stackrel{\text { ¿ }}{>}$ & & & & & & \\
\hline 它 & $\underset{>}{J}$ & \multirow{4}{*}{ 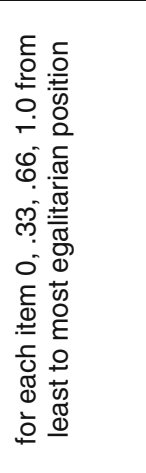 } & \multirow{4}{*}{ 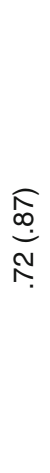 } & \multirow{4}{*}{ 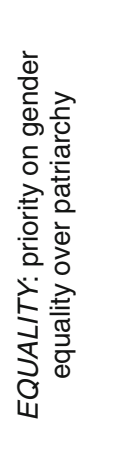 } & \multirow{4}{*}{ 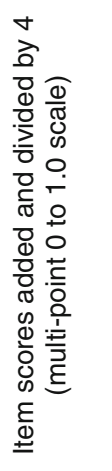 } & & \\
\hline 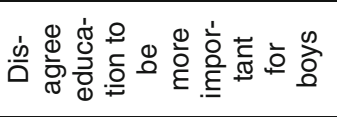 & $\stackrel{\widetilde{~}}{>}$ & & & & & & \\
\hline 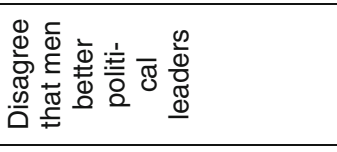 & $\bar{\varphi}$ & & & & & & \\
\hline 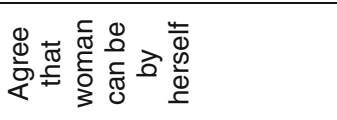 & 号 & & & & & & \\
\hline$\stackrel{\mathscr{\infty}}{\underset{\Phi}{\Phi}}$ & 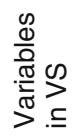 & 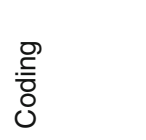 & 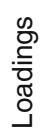 & $\begin{array}{l}\frac{x}{0} \\
\frac{0}{0} \\
\frac{.0}{0} \\
\omega\end{array}$ & $\begin{array}{l}\text { D } \\
\text { 离 } \\
\text { œ }\end{array}$ & 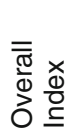 & 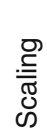 \\
\hline
\end{tabular}


Table 2 Ecological regressions explaining self-expression values with cognitive mobilization

\begin{tabular}{llll}
\hline Predictors & \multicolumn{2}{l}{ Dependent variable: self-expression values 1995-2005 } \\
\cline { 2 - 4 } & \multicolumn{1}{l}{ Model 1 } & Model 2 & Model 3 \\
\hline Intercept & $.19(9.79)^{* * *}$ & $.28(13.89)^{* * *}$ & $.18(9.77)^{* * *}$ \\
Cognitive mobilization & $.38(13.00)^{* * *}$ & & $.32(8.82)^{* * *}$ \\
Western tradition & & $.27(7.63)^{* * *}$ & $.08(2.61)^{*}$ \\
Adjusted $R^{2}$ & .67 & .40 & .69 \\
$N$ & 83 & 87 & 83
\end{tabular}

Entries are unstandardized regression coefficients with $T$-ratios in parentheses. Significance levels: $* p<.10 ; * * p<.01 ; * * * p<.001$

Based on the data and variables just described we test our three hypotheses on the societal-level and the individual level. At both levels of analysis, the questions we try to answer are (1) whether units of observation that are more advanced in cognitive mobilization are also more advanced in self-expression values, (2) whether units of observation that are more advanced in self-expression values follow a more agentic life strategy, and (3) whether units of observation driven by a more agentic life strategy reach higher levels of life satisfaction.

\section{Findings}

Table 2 shows the result of regressions when entire societies are the unit of analysis. The table analyzes a society's base level of self-expression values as a function of cognitive mobilization and western traditions. Considered separately, both western traditions and cognitive mobilization influence a society's base level of self-expression values positively: societies with stronger western traditions and cognitively mobilized societies exhibit higher base levels of self-expression values. Under mutual controls, however, it turns out that the self-expression effect of cognitive mobilization outperforms that of western traditions. Thus, the effect of cognitive mobilization is not contingent on western traditions: even disconnected from these traditions does cognitive mobilization nurture self-expression values. In other words, cognitively mobilized societies are not more self-expressive because they have stronger western traditions but because they are cognitively mobilized. The scatterplot in Fig. 3 visualizes the utility-values link that ties self-expression values to cognitive mobilization.

In social science there is always the possibility of the 'ecological fallacy,' which means to mistakenly infer from macro-level linkages that the same linkages exist at the microlevel (Robinson 1950; Alker 1969). Indeed many linkages that explain differences between societies may not explain differences between individuals within societies (Przeworski and Teune 1970). In this case, the macro-level linkages are ecological artifacts of aggregation because they have no micro-foundation.

Table 3 examines the micro-foundation of the utility-value link, using a multi-level model, often also referred to as a 'hierarchical linear model' (Bryk and Raudenbush 2002). The coefficients of the societal-level component of the model are not exactly identical to those in the ecological regression models because missing data on some individual-level variables reduce the sample from 83 to 78 societies. Still, we find cognitive mobilization to 


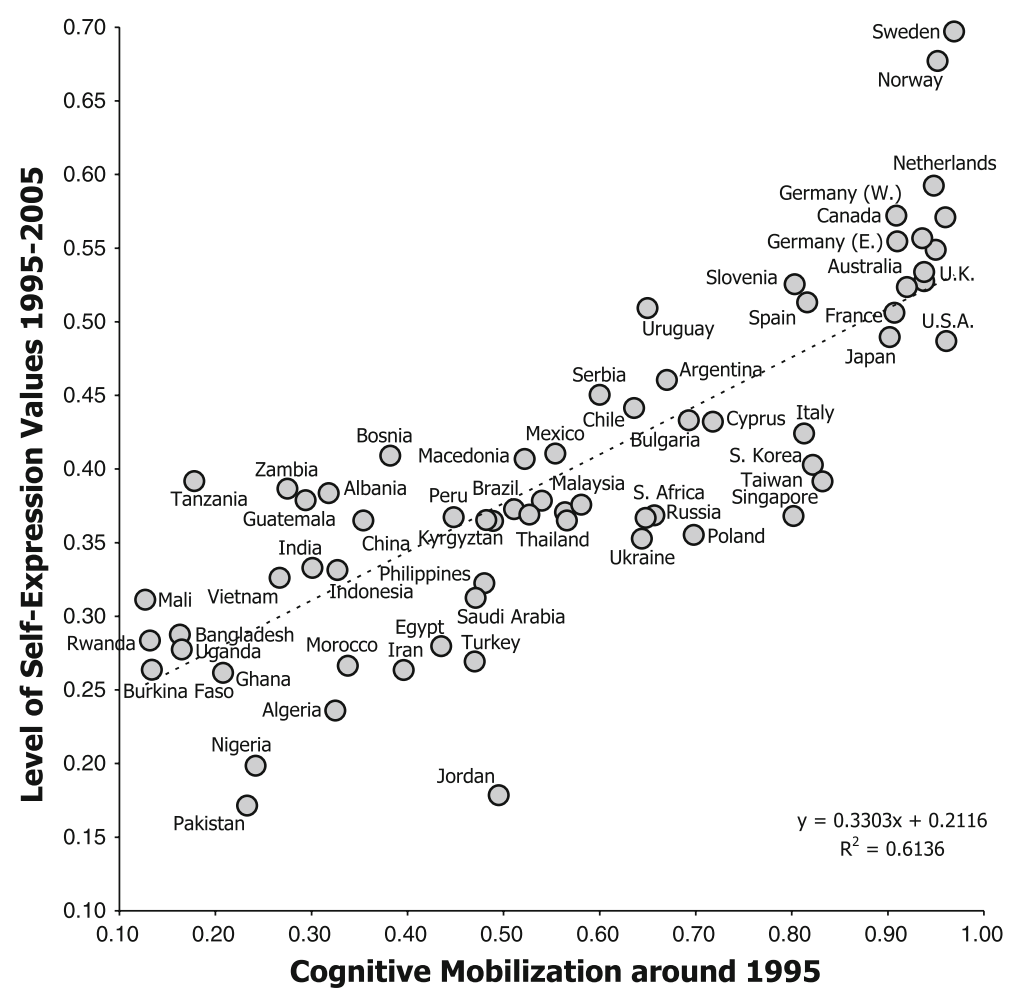

Fig. 3 An illustration of the utility-value link

enhance the base level of self-expression values in a society more than double as much as western traditions do. Looking at the individual-level findings, the model provides a nice illustration of the utility logic. Education offers people greater opportunities to thrive almost everywhere and so education should have a universally positive effect on selfexpression values, irrespective of societal-level conditions. This is indeed what we find: one's level of education shows a generally positive and highly significant effect on one's self-expression values, even taking societal-level variation of this effect into account. Yet, the size of education's self-expression effect is partially moderated by cognitive mobilization at the societal-level: even though the effect of education is always positive, it tends to be bigger in cognitively mobilized societies. This makes sense in the utility logic: in cognitive mobilized societies, a larger number and greater diversity of occupations and activities is available in which education pays off, and so education offers greater thriving opportunities in cognitively mobilized societies. Education has greater utility for personal growth in cognitively mobilized societies, which is reflected in a stronger effect on selfexpression values in such societies.

What about the values-strategy link that is supposed to tie agentic life strategies to selfexpression values? We understand agentic life strategies as a matter of degree: it is the relative weight that feelings of agency have in shaping people's life satisfaction. To measure this weight, we calculate for each society the average strength by which people's feelings of agency impact on their life satisfaction, which becomes manifest in the magnitude of the coefficient that regresses life satisfaction on agency feelings. However, we are 
Table 3 Multi-level model explaining self-expression values

Entries are unstandardized regression coefficients with $T$-ratios in parentheses. Individual-level variables are centered on society means; society-level variables are centered on the global mean. Models calculated with HLM 6.01. Pooled data from WVS rounds III (1995-1997) to V (2005-2007). Significance levels: $* p<.10$; ** $p<.01$; $* * * p<.001$

$$
\text { Predictors }
$$

Dependent variable: self-expression values 1995-2005

$\begin{array}{ll}\text { Intercept } & .39(53.63)^{* * *} \\ \text { Societal-level effects } & .27(6.54)^{* * *} \\ \text { Cognitive mobilization } & .11(3.27)^{* * *} \\ \text { Western tradition } & \\ \text { Individual-level effects } & -.01(-10.70)^{* * *} \\ \text { Biological age } & .03(14.48)^{* * *} \\ \text { Female sex } & .05(7.33)^{* * *} \\ \text { Income level } & .11(17.88)^{* * *} \\ \text { Education level } & .11(3.98)^{* * *} \\ \quad \text { Cognitive mobilization } & \text { Not significant } \\ \text { Western tradition } & \\ \text { Explained variances } & 10.3 \% \\ \text { Within-society variation of DV } & 69.0 \% \\ \text { Between-society variation of DV } & 45.1 \% \\ \text { Variation in effect of education } & 149,887 \text { Respondents } \\ N \quad \text { in } 78 \text { societies }\end{array}$

interested in the relative weight of feelings agency, as compared to the well-being effect of monetary saturation whose materialist nature sets it in stark contrast to such an idealistic aspect as agency. Thus, we calculate for each society how much stronger or weaker people's life satisfaction is shaped by agency feelings than by monetary saturation, subtracting the well-being effect of monetary saturation from that of agency feelings. In other words, we count the monetary against the agentic wellbeing effects and average these differences over entire populations. This measures per society the relative strength of agentic life strategies, which is the dependent variable in Table 4.

The regression results in Table 4 evidence the value-strategy link that is supposed to tie agentic life strategies to self-expression values. This link is positive and highly significant and it does not break down under control of western traditions. It is by no means so that agentic life strategies are tied to self-expression values only in western societies, as cultural relativists might suspect. Put differently, agentic life strategies are not stronger in selfexpressive societies because these societies are more western but because they are more self-expressive. A visual illustration of the value-strategy link is provided by the scatterplot in Fig. 4.

As with the utility-value link, the value-strategy link has a micro-foundation too, and quite in a Maslowian sense. For this matter consider that we can calculate for each individual the residual in life satisfaction that is unexplained by this individual's agency feeling. This tells us how much a person's satisfaction is unrelated to agency, which is a directly inverse indicator of agency-driven satisfaction, that is, agentic life strategies. Now guess what is the best individual-level predictor of someone's agentic life strategy? The answer is monetary saturation. Among those respondents in VS III to V whose life satisfaction falls short of what their agency feelings predict $(N=112,487)$, monetary satisfaction reduces the extent to which life satisfaction falls short of agency feelings in highly significant ways. Specifically, a one unit increase in monetary saturation decreases the 
Table 4 Ecological regressions explaining the relative strength of agentic life strategies with selfexpression values

\begin{tabular}{llll}
\hline Predictors & \multicolumn{4}{l}{ Dependent variable: relative strength of agentic life strategy 1995-2005 } \\
\cline { 2 - 4 } & \multicolumn{1}{l}{ Model 1 } & Model 2 & Model 3 \\
\hline Intercept & $-.55(-8.41)^{* * *}$ & $-.34(-8.18)^{* * *}$ & $-.53(8.02)^{* * *}$ \\
Self-expression values & $.84(5.45)^{* * *}$ & & $.74(3.60)^{* * *}$ \\
Western tradition & & $.27(3.71)^{* * *}$ & Not significant \\
Adjusted $R^{2}$ & .29 & .16 & .28 \\
$N$ & 71 & 70 & 70
\end{tabular}

Entries are unstandardized regression coefficients with $T$-ratios in parentheses. Significance levels: $* p<.10 ; * * p<.01 ; * * * p<.001$

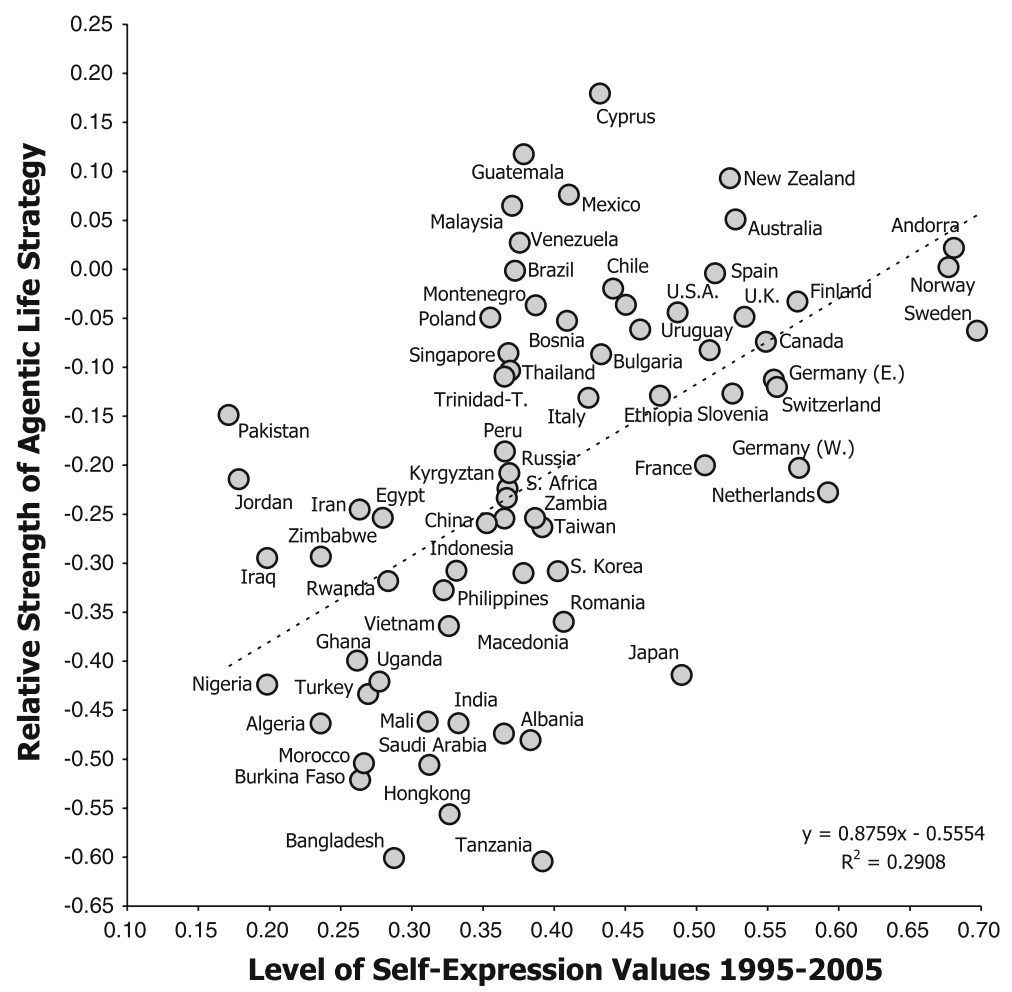

Fig. 4 An illustration of the value-strategy link

extent to which life satisfaction falls short of agency by .26 units on a scale range from -1.0 to +1.0 . This reduction operates in a confidence interval between .25 and .27 units and explains $13.7 \%$ of the total variation in agentic life strategies (or their inverse, to be more precise). Counting out from this relationship the variation that is located between societies, a one unit increase in monetary saturation reduces the extent to which life satisfaction falls short of agency by .24 units, operating in a confidence interval between .244 and .235 units, still accounting for $10.2 \%$ of the total variation in agentic life 
Table 5 Ecological regressions explaining life satisfaction with the relative strength of agentic life strategies

\begin{tabular}{llll}
\hline Predictors & \multicolumn{2}{l}{ Dependent variable: life satisfaction 1995-2005 } \\
\cline { 2 - 4 } & Model 1 & Model 2 & Model 3 \\
\hline Intercept & $.68(41.64)^{* * *}$ & $.48(24.77)^{* * *}$ & $.59(21.16)^{* * *}$ \\
Agentic life strategies & $.34(5.89)^{* * *}$ & & $.26(4.43)^{* * * *}$ \\
Western tradition & & $.27(7.99)^{* * *}$ & $.16(4.12)^{* * *}$ \\
Adjusted $R^{2}$ & .33 & .42 & .47 \\
$N$ & 71 & 89 & 70
\end{tabular}

Entries are unstandardized regression coefficients with $T$-ratios in parentheses. Significance levels: $* p<.10 ; * * p<.01 ; * * * p<.001$

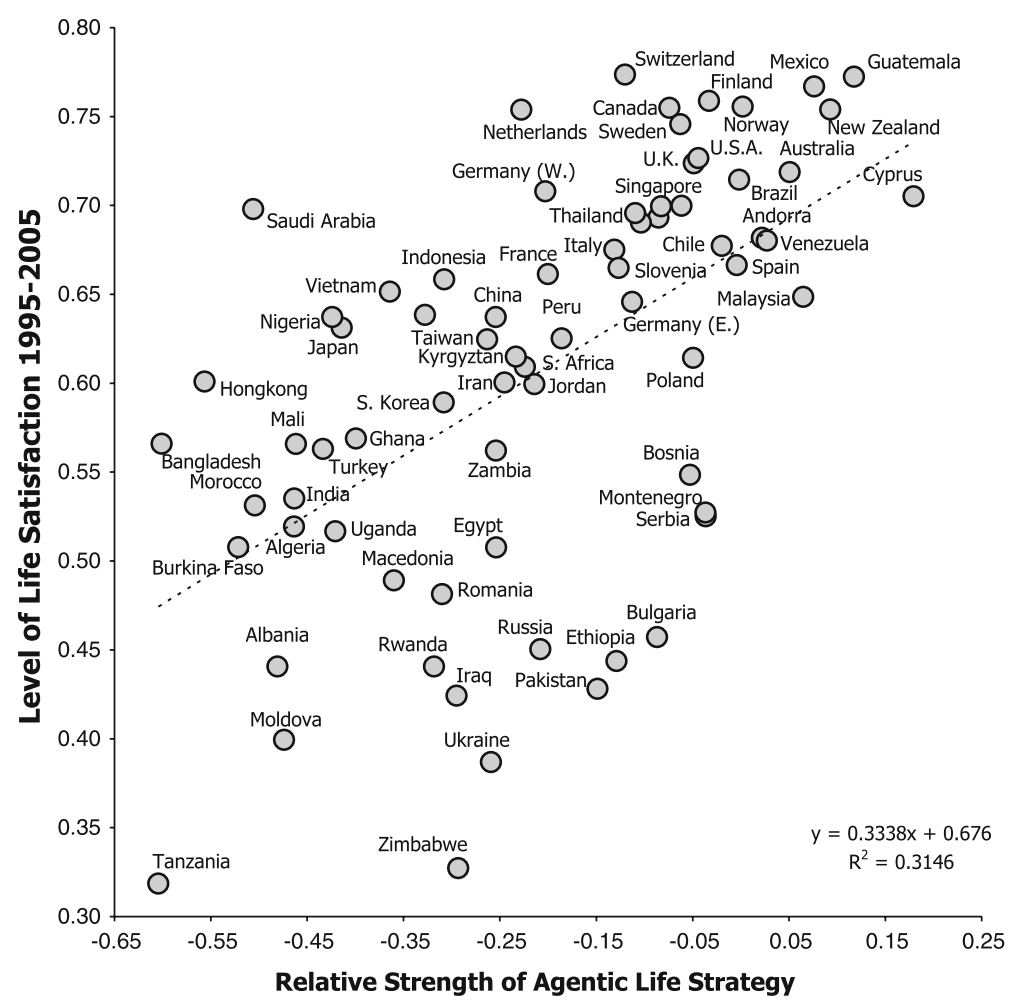

Fig. 5 An illustration of the strategy-wellbeing link

strategies. Hence, material needs must be satisfied first before agency can become the driver of life satisfaction.

Let us now consider the strategy-wellbeing link that is supposed to tie the level of life satisfaction to the strength of agentic life strategies. The regression analyses in Table 5 and the scatterplot in Fig. 5 document that this link, too, is statistically significant, operates in the expected direction, and does not vanish when one takes the strength of a society's western tradition into account. Thus, when more people in a society follow agentic life strategies, this 
society's base live satisfaction level tends to be higher. And this relationship does not exist because societies with stronger western traditions nurture both agentic life strategies and high levels of life satisfaction. These findings seem to indicate that even though various maximization strategies yield some level of satisfaction, certain strategies yield more than others. Specifically, agentic strategies yield particularly high rates of life satisfaction.

Table 6 shows a multi-level model that examines the micro-foundation of the strategywellbeing link. The societal-level component of the multi-level model corresponds to the

Table 6 Multi-level model explaining life satisfaction

Entries are unstandardized regression coefficients with $T$ ratios in parentheses. Individuallevel variables are centered on society means; society-level variables are centered on the global mean. Models calculated with HLM 6.01. Pooled data are from WVS rounds III (19951997), to V (2005-2007). Significance levels: $* p<.10$; $* * p<.01 ; * * * p<.001$

\begin{tabular}{|c|c|}
\hline Predictors & $\begin{array}{l}\text { Dependent variable: } \\
\text { life satisfaction } \\
\text { 1995-2005 }\end{array}$ \\
\hline Intercept & $.59(60.80)^{* * *}$ \\
\hline \multicolumn{2}{|l|}{ Societal-level effects } \\
\hline Agentic strategies (prevalence) & $.27(4.58)^{* * *}$ \\
\hline Western tradition & $.17(4.99)^{* * * *}$ \\
\hline \multicolumn{2}{|l|}{ Individual-level effects } \\
\hline Biological age & $-.01(-2.62) * * *$ \\
\hline Female sex & $.01(6.09)^{* * *}$ \\
\hline Income level & $.04(7.18)^{* * *}$ \\
\hline Education level & Not significant \\
\hline Communion emphasis & $.10(6.69)^{* * *}$ \\
\hline Agentic strategies (prevalence) & Not significant \\
\hline Western tradition & Not significant \\
\hline Monetary saturation & $.53(25.46)^{* * *}$ \\
\hline Agentic strategies (prevalence) & $-.41(-3.30)^{* * * *}$ \\
\hline Western tradition & Not significant \\
\hline Agency feeling & $.21(10.93)^{* * *}$ \\
\hline Agentic strategies (prevalence) & $.49(3.34)^{* * *}$ \\
\hline Western tradition & Not significant \\
\hline Agency $\times$ saturation & $-.06(-4.38) * * *$ \\
\hline Agentic strategies (prevalence) & Not significant \\
\hline Western tradition & Not significant \\
\hline Agency $\times$ communion & Not significant \\
\hline Agentic strategies (prevalence) & Not significant \\
\hline Western tradition & Not significant \\
\hline Communion $\times$ saturation & $-.07(-3.25)^{* *}$ \\
\hline Agentic strategies (prevalence) & Not significant \\
\hline Western tradition & Not significant \\
\hline \multicolumn{2}{|l|}{ Explained variances } \\
\hline Within-society variation of DV & $36.0 \%$ \\
\hline Between-society variation of DV & $47.6 \%$ \\
\hline Variation in effect of communion & $0 \%$ \\
\hline Variation in effect of saturation & $85.4 \%$ \\
\hline Variation in effect of agency & $55.1 \%$ \\
\hline$N$ & $\begin{array}{l}\text { 155,611 Respondents } \\
\text { in } 76 \text { societies }\end{array}$ \\
\hline
\end{tabular}


findings that we have seen in the ecological regressions, so the novelty is in the individuallevel component. Here we test the relative impact of three maximization strategies on people's life satisfaction, including (a) a communal strategy driven by communion emphasis, (b) a monetary strategy driven by monetary saturation, and (c) an agentic strategy driven by agency feelings. We are not only interested in the relative size of these strategies' general effects but also whether and in what direction these effects are moderated by societal-level characteristics.

Apparently, each strategy contributes significantly and positively to life satisfaction and this is generally so, even taking societal-level moderations into account. Generally, monetary saturation shows the strongest, agency feelings the second strongest, and communion emphasis the third strongest effect on life satisfaction. In contrast to what much of the psychological literature assumes (but see Baumeister et al. 2009), agency feelings and communion emphasis are in no trade-off relation as strategies to maximize life satisfaction. Otherwise, their interaction should be significantly negative. In fact, however, it is significantly positive: agency feelings and communion emphasis amplify each others' impact on life satisfaction. But both strategies interact negatively with monetary saturation, which indicates a trade-off relation: a decreasing impact of monetary saturation on life satisfaction amplifies the wellbeing effects of agency and communion, and vice versa. Looking at moderations, the wellbeing effect of communion does not seem to vary with societallevel characteristics but the effects of saturation and agency do, and they do so in a reverse way. When many people in a society follow an agentic satisfaction strategy, an individual

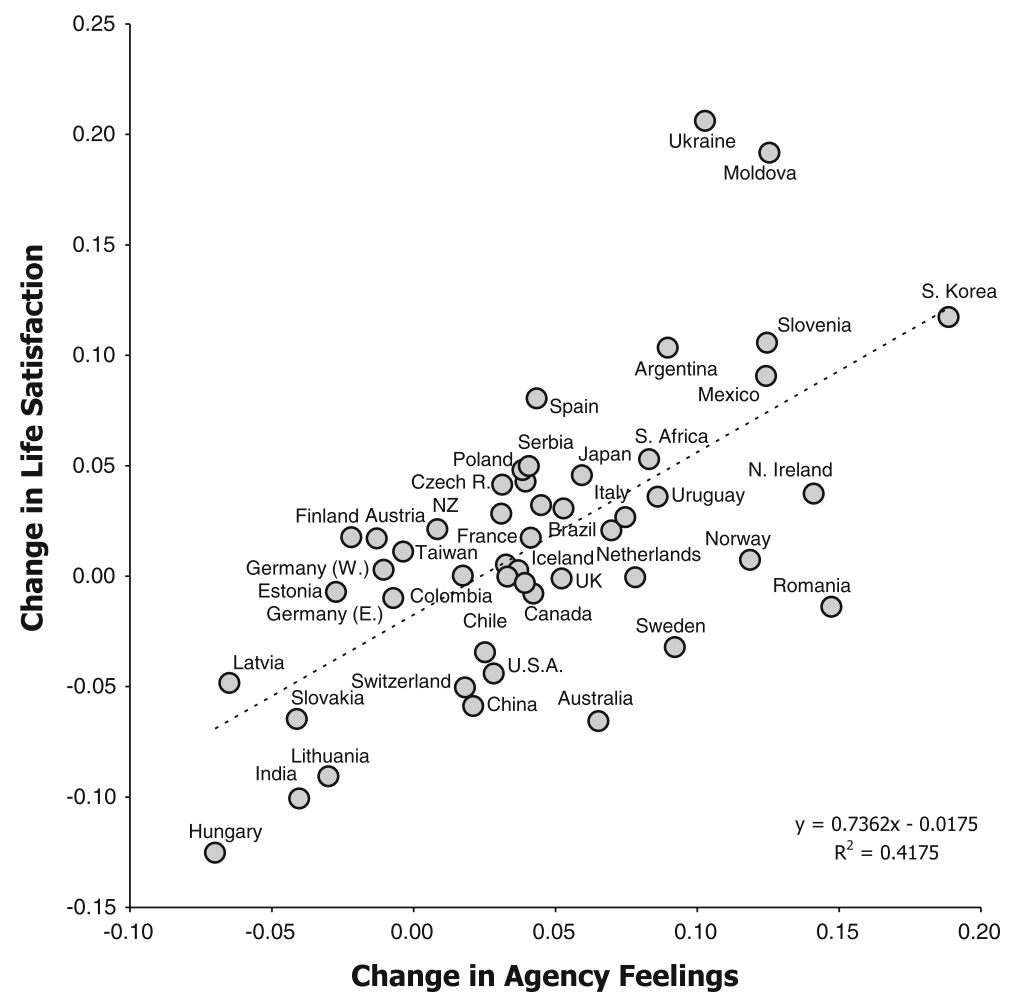

Fig. 6 Changes in agency feelings and life satisfaction 
yields much less satisfaction from more monetary saturation and more satisfaction from stronger agency feelings. The positive moderation of agency's individual-level effect by the prevalence of agentic strategies at the societal-level illustrates a confirmation mechanism known as 'social proof' in psychology (Cialdini 1993): when many people in a society follow agentic strategies one feels confirmed when one does so oneself, which increases agency's satisfaction payoff.

In a dynamic perspective, our findings imply that rising feelings of agency bring rising levels of life satisfaction. The evidence in Fig. 6 confirms this expectation. The graphic shows the extent and direction in which societies experienced changes in their overall feelings of agency and in life satisfaction from the earliest to the latest available survey in the VS. We delimit ourselves to changes that stretch over at least three rounds of the VS, which implies a minimum temporal distance of 15 years. It is clear that changes in agency feelings correspond with changes in life satisfaction. Controlling the initial level of life satisfaction that was given right at the beginning of the changes depicted here does not diminish the relationship.

\section{Discussion}

This article provided evidence for an evolutionary sequence of adaptive linkages that anchor agency in the human motivational system. First, there is utility-value link through which people learn to value the opportunities that have most utility under given existential conditions. The logic of this link ties the rise of self-expression values to the thriving opportunities that emerge with the cognitive mobilization of societies. Second, there is a value-strategy link through which people translate their values into corresponding maximization strategies. This link ties the rise of agentic maximization strategies to the emergence of self-expression values. Third, there is a strategy-wellbeing link that gives different maximization strategies a differential satisfaction yield, in line with a Maslowian logic due to which self-actualizing strategies yield the most satisfaction. This link ties high levels of life satisfaction to agentic maximization strategies.

We see the strength of our evidence in its spatial scope and generality. We used representative data that can be generalized to entire national populations and we covered a wide, indeed global, range of societies at different levels of economic development and of very different cultural roots. Insofar we can say that the evidence for the adaptive links we have been showing is indeed broad and general. Also, we could show that the adaptive links operate at different levels of analyses and that what we saw at the macro-level of societies has a micro foundation among individuals. This further speaks to the validity of our findings.

However, there is one serious limitation. Our evidence is mostly cross-sectional and lacks a more extended longitudinal component. In lack of extensive longitudinal data it is impossible to sort out what came first and what followed, and so causality cannot be fixed. Without the means to test causality empirically, the causal direction in a proven relationship remains a matter of theoretical plausibility. Here we think we provide a model that allows for some plausible causal interpretations that can be tested in the future. For this to become possible, more longitudinal data must become available, even though some supportive evidence is available already now. Specifically, Inglehart et al. (2008) have shown that rising levels of happiness over the past 20 years in some 50 societies are related to an increasing sense of freedom, which in turn is related to rising self-expression values. Yet, these authors just report findings, without situating them in a broader theoretical 
framework from which to derive concise sets of testable hypotheses. The human development framework provided here does formulate such sets of hypotheses and showed some first confirmatory evidence. This evidence seems broad and deep enough to serve as a starting point for further longitudinal and experimental studies into the links proposed here.

Open Access This article is distributed under the terms of the Creative Commons Attribution Noncommercial License which permits any noncommercial use, distribution, and reproduction in any medium, provided the original author(s) and source are credited.

\section{References}

Acemoglu, D., \& Robinson, J. A. (2006). Social origins of democracy and dictatorship. New York: Cambridge University Press.

Alker, H. R., Jr. (1969). A typology of ecological fallacies. In M. Dogan \& S. Rokkan (Eds.), Quantitative ecological analysis in the social sciences (pp. 69-86). Cambridge: MIT.

Axelrod, R. (1986). An evolutionary approach to norms. American Political Science Review, 80, 1095-1111.

Bakan, D. (1966). The duality of human existence: An essay on psychology and religion. Boston: Beacon.

Barber, N. (2008). Evolutionary explanations for societal differences and historical change. Cross-Cultural Research, 41, 123-148.

Baumeister, R. F., Masicampo, E. J., \& DeWall, C. N. (2009). Prosocial benefits of feeling free. Personality and Social Psychology Bulletin, 35, 260-268.

Birch, C., \& Cobb, J. B., Jr. (1981). The liberation of life: From the cell to the community. Cambridge: Cambridge University Press.

Boyd, R., \& Richardson, P. J. (2005). How microevolutionary processes give rise to history. In R. Boyd \& P. J. Richardson (Eds.), The origin and evolution of cultures (pp. 287-309). New York: Oxford University Press.

Bryk, A., \& Raudenbush, S. (2002). Hierarchical linear models. Thousand Oaks: Sage.

Carneiro, R. (2003). Evolutionism in cultural anthropology. Boulder: Westview.

Cialdini, R. B. (1993). Influence: Science and practice. New York: Harper Collins.

Coleman, J. S. (1990). Foundations of social theory. Cambridge: Harvard University Press.

Dalton, R. J. (2006). Citizen politics. Washington, DC: PQ Press.

Deci, E. L., \& Ryan, R. M. (2000). The what and why of goal pursuits: Human needs and the selfdetermination of behavior. Psychological Inquiry, 11, 227-268.

Delhey, J. (2010). From material to postmaterial happiness? National affluence and determinants of life satisfaction in cross-national perspective. World Values Research, 2, 30-54.

Diamond, J. (2005). Collapse: How societies chose to fail or succeed. New York: Viking.

Diener, E., Lucas, R. E., \& Scollon, C. N. (2006). Beyond the hedonic treadmill: Revising the adaptation theory of well-being. American Psychologist, 61, 305-314.

Diener, E., \& Oishi, S. (2000). Money and happiness: Income and subjective well-being across nations. In E. Diener \& E. Suh (Eds.), Subjective well-being across cultures. Cambridge: MIT.

Drucker, P. (1993). Post-capitalist society. New York: Harper Collins.

Dunbar, R., Knight, C., \& Power, C. (1999). An evolutionary approach to human culture. In R. Dunbar, C. Knight, \& C. Power (Eds.), The evolution of culture (pp. 1-14). New Brunswick: Rutgers University Press.

Durham, W. H. (1991). Coevolution: Genes, culture, and human diversity. Stanford: Stanford University Press.

Elias, N. (2004). Knowledge and power: An interview by Peter Ludes. In N. Stehr \& V. Meja (Eds.), Society \& knowledge (pp. 203-242). New Brunswick: Transaction. [1984].

Flanagan, S. (1987). Value change in industrial society. American Political Science Review, 81, 1303-1319.

Flanagan, S., \& Lee, A.-R. (2001). Value change and democratic reform in Japan and Korea. Comparative Political Studies, 33, 626-659.

Florida, R. (2002). The rise of the creative class. New York: Basic Books.

Foerster, J., Higgins, E., \& Idson, L. (1998). Approach and avoidance strength during goal attainment: Regulatory focus and the 'goal looms larger' effect. Journal of Personality and Social Psychology, 75, 1115-1131.

Gerring, J., Bond, P., Barndt, W. T., \& Moreno, C. (2005). Democracy and economic growth. World Politics, 57, 323-364. 
Guisinger, S., \& Blatt, S. (1994). Individuality and relatedness. American Psychologist, 49, 104-111.

Hagerty, M., \& Veenhoven, R. (2006). Rising happiness in nations, 1946-2004. A reply to Easterlin. Social Indicators Research, 79, 421-436.

Haller, M., \& Hadler, M. (2004). Happiness as an expression of freedom and self-determination: A comparative multilevel analysis. In W. Glatzer, S. von Below, \& M. Stoffregen (Eds.), Challenges for quality of life in the contemporary world. Dordrecht: Kluwer.

Huntington, S. P. (1996). The clash of civilizations and the remaking of the world order. New York: Simon \& Schuster.

Inglehart, R. (1977). The silent revolution. Princeton: Princeton University Press.

Inglehart, R. (1990). Culture shift in advanced industrial societies. Princeton: Princeton University Press.

Inglehart, R. (1997). Modernization and postmodernization: Cultural, economic and political change in 43 societies. Princeton: Princeton University Press.

Inglehart, R., Foa, R., Peterson, C., \& Welzel, C. (2008). Development, freedom, and rising happiness. Perspective on Psychological Science, 3, 264-285.

Inglehart, R., \& Welzel, C. (2005). Modernization, cultural change and democracy: The human development sequence. New York: Cambridge University Press.

Kluckhohn, C. (1951). Value and value orientation in the theory of action. In T. Parsons \& E. Shils (Eds.), Towards a general theory of action. Cambridge: Harvard University Press.

Lykken, D. (2000). Happiness, the nature and nurture of joy and contentment. New York: St. Martin's Griffin.

Marshall, M. G., \& Jaggers, K. (2000). Polity IV project (data users manual). College Park: University of Maryland.

Maryanski, A., \& Turner, J. H. (1992). The social cage: Human nature and the evolution of society. Stanford: Stanford University Press.

Maslow, A. (1988). Motivation and personality (3rd ed.). New York: Harper \& Row. [1954].

McAdams, D. P. (1993). The stories we live by. New York: Harper Collins.

Meyer, J. W., Boli, J., Thomas, G. M., \& Ramirez, F. O. (1997). World society and the nation-state. American Journal of Sociology, 103, 144-181.

Modelski, G., \& Gardner, P. (2002). Democratization in long perspective. Technological Forecasting and Social Change, 69, 359-376.

Nolan, P., \& Lenski, G. (1999). Human societies (8th ed.). New York: McGraw Hill.

Parsons, T. (1964). Evolutionary universals in society. American Sociological Review, 29, 339-357.

Peterson, C., Park, N., \& Seligman, M. E. P. (2005). Orientations to happiness and life satisfaction: The full life versus the empty life. Journal of Happiness Studies, 6, 25-41.

Przeworski, A., \& Teune, H. (1970). The logic of comparative social inquiry. New York: Wiley.

Reinert, E. S. (2007). How rich countries got rich ... and why poor countries stay poor. New York: Carroll \& Graf.

Robinson, W. S. (1950). Ecological correlations and the behavior of individuals. American Sociological Review, 15, 351-357.

Rokeach, M. (1968). Beliefs, attitudes and values. San Francisco: Jossey-Bass.

Schwartz, S. H. (2007). Value orientations: Measurement, antecedents and consequences across nations. In R. Jowell, C. Roberts, R. Fitzgerald, \& G. Eva (Eds.), Measuring attitudes cross-nationally (pp. 161193). London: Sage.

Sen, A. (1999). Development as freedom. New York: Alfred Knopf.

Toffler, A. (1990). Power shift: Knowledge, wealth and violence at the edge of the $21^{\text {st }}$ century. New York: Bantham.

Tooby, J., \& Cosmides, L. (2005). Evolutionary psychology: Conceptual foundations. In D. M. Buss (Ed.), Evolutionary psychology handbook. New York: Wiley.

Veenhoven, R. (2000). Freedom and happiness: A comparative study in forty-four nations in the early 1990s. In E. Diener \& E. Suh (Eds.), Subjective well-being across cultures (pp. 257-288). Cambridge: MIT.

Warsh, D. (2006). Knowledge and the wealth of nations. New York: W.W. Norton.

Welzel, C. (2006). Democratization as an emancipative process. European Journal of Political Research, $45,871-896$.

Welzel, C. (2007). Do levels of democracy depend on mass attitudes? International Political Science Review, 28, 397-424.

Welzel, C., Inglehart, R., \& Klingemann, H. D. (2003). The theory of human development: A cross-cultural analysis. European Journal of Political Research, 42, 341-379. 